\title{
CLOSING THE IMPLEMENTATION GAP: MOVING FORWARD WITH THE UNITED NATIONS GUIDELINES FOR THE ALTERNATIVE CARE OF CHILDREN
}

\author{
Jennifer Davidson
}

\begin{abstract}
This paper offers a brief picture of an international policy framework, the United Nations Guidelines for the Alternative Care of Children, and their development from initial conception within the Committee on the Rights of the Child to today. It provides an overview of the key principles of these Guidelines, drawing from a new resource developed to support their implementation around the world, entitled Moving Forward: Implementing the Guidelines for the Alternative Care of Children. This overview includes an explanation of the "necessity" and "suitability" principles; the importance of prevention alongside a robust "gatekeeping" function; the fundamental need for developing a genuine range of options; and the significance of focusing on "de-institutionalising the care system". This article aims to offer something of a road map, identifying along the way a number of key milestones negotiated for children's rights to be fully realised in alternative care. While this is a long road, the course has been internationally agreed.
\end{abstract}

Keywords: children's rights, alternative care, child protection, deinstitutionalisation, international guidelines, implementation

Acknowledgements: The following article was originally presented by Jennifer Davidson as a plenary contribution to the international FICE Congress in Berne, Switzerland on October 11, 2013. The content is drawn closely from the Moving Forward implementation handbook authored by N. Cantwell, J. Davidson, S. Elsley, I. Milligan, and N. Quinn. The Moving Forward handbook, on which this paper was based, was supported by the International Social Service, Oak Foundation, SOS Children's Villages International, and UNICEF. Underlying research materials related to this paper can be accessed at: www.alternativecareguidelines.org

Jennifer Davidson was the Director of the Moving Forward Project, and is the Director of the Centre for Excellence for Looked After Children (CELCIS) at the University of Strathclyde, Lord Hope Building, 141 St James Road, Glasgow G4 0LT.

E-mail: jennifer.davidson@strath.ac.uk 
One of the many creative outputs from an international conference for young people with experience of care (in parallel with the 2004 FICE Congress) was a message painted on canvas that now hangs on our office walls at the Centre for Excellence for Looked After Children (CELCIS) at the University of Strathclyde. It hangs as a reminder of the empowering role that we are called to play in children and young people's lives; the artwork announces: “Don’t forget it's our lives!” This declaration was the young people’s key message to the adults involved in their remarkable, inspiring, and complicated lives.

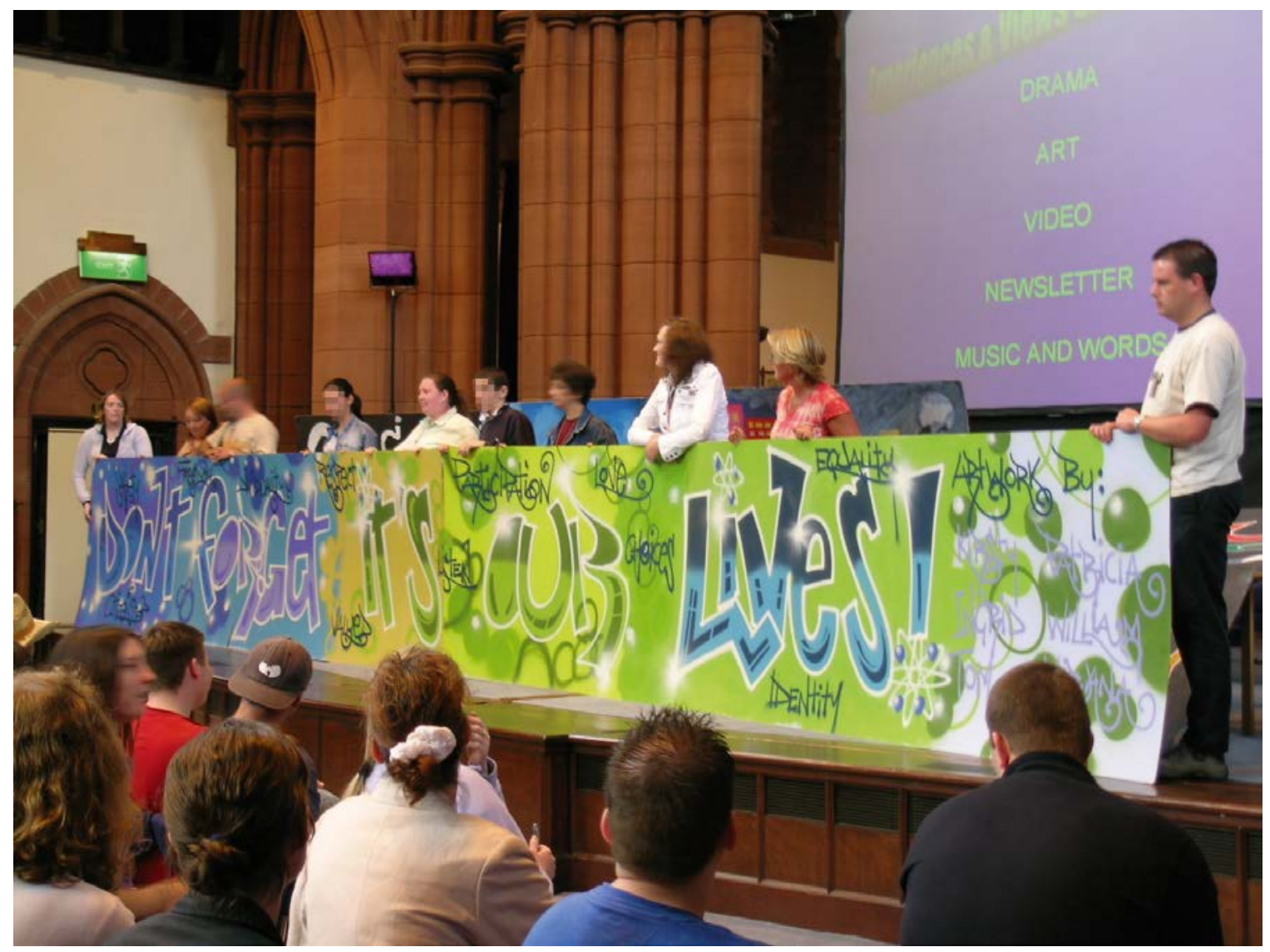

Photo taken at the 2004 FICE Congress, University of Strathclyde, Scotland.

Perhaps similarly affecting, the powerful photos of Syria's children alerting us to the terrible complexity of living in a war zone, presented at the FICE Congress 2014 Opening Ceremony, are images that will surely remain with all those who were present. Some may also remember that the 2004 FICE Congress took place just after the Russian tragedy in Beslan, which we had watched with our hearts in our mouths, as the horror unfolded on our TV screens.

Pausing to remember the very difficult conditions for children around the world at both the 2004 and 2014 FICE Congresses surely begs the question: What has changed in 10 years? Certainly, we can confidently say that not enough has changed. However, with our eyes firmly fixed on the importance of realising children and young people's rights, today I would like to highlight one important international development over this past decade. 
The last decade has seen big steps taken toward the goal of placing children's rights at the heart of alternative care.

(Cantwell, Davidson, Elsley, Milligan, \& Quinn, 2012, p. 14)

While I cannot speak about changes in direct practice for children in your particular communities, I would like to draw our attention to a substantial change at the international policy level that has taken place in recent years, and which has the potential to have lasting effects on the experiences and outcomes of some of the most vulnerable children and young people we work with. That is, those children who are living out of their parents' care. These contributed to the development of the Guidelines for the Alternative Care of Children (the Guidelines) (United Nations General Assembly, 2009)

The following article will briefly outline the development of these international Guidelines from their initial starting place within the Convention on the Rights of the Child (CRC), and will offer an overview of the key principles of the Guidelines, drawing from a new resource developed to support the implementation of these Guidelines around the world entitled Moving Forward: Implementing the Guidelines for the Alternative Care of Children (Cantwell et al., 2012). This paper aims to offer something of a road map, identifying a number of key milestones in the path negotiated for children's rights to be fully realised in alternative care. While this is a long road, the course has been internationally agreed.

\section{The United Nations Convention on the Rights of the Child}

The U.N. Committee that monitors the implementation of the Convention on the Rights of the Child (CRC) (United Nations, 1989) in policy and practice by member states has long had an "obsession" (Zermatten, 2012) with services for children who are at risk of, or in need of alternative care. This is due in part to the large numbers of children living in alternative care, and in particular "due to the reasons that children are unnecessarily there (such as poverty); due to the poor conditions when care is provided; and due to the slow progress on improving conditions and reasons for coming into care in the first place" (Zermatten, 2012, p. 1).

This question of how best to realise children's rights in the context of alternative care formed the basis of the annual Day of Discussion in 2005 hosted by the CRC Committee. This was supported by an earlier call for international standards, led by UNICEF and International Social Services. In the following years, the answers were sought through a collaborative effort between governments, UNICEF, NGOs, specialists, and young people with experience of alternative care from all regions of the world, resulting in the Guidelines for the Alternative Care of Children.

\section{The Guidelines for the Alternative Care of Children}

The Guidelines offer a policy framework at an international level that is more coherent than anything previous, and this is shaping a more human rights-based approach to providing services for children and young people whose families are unable to care for them. Children's rights, at an international level, have been applied specifically to the context of alternative care and these have been recognised around the world by all governments. 
The Guidelines were unanimously welcomed by the General Assembly as a nonbinding text in 2009: the fact this was unanimous makes them a very strong tool. Since then the CRC Committee has used the principle of these Guidelines in almost all its concluding observations: very few state parties escape criticism on this theme. Additionally, the potential of the Guidelines is not limited to the boundaries of the influence of the CRC Committee alone. For examples, the Committee on the Rights of Persons with Disabilities (United Nations Human Rights Council, 2012) has for the first time highlighted the concerns of children with disabilities in alternative care by incorporating the issues identified in the Guidelines into their concluding observations. The African Committee of Experts on the Rights and Welfare of the Child (ACERWC) in its first general comment also makes specific reference to the Guidelines (ACERWC, 2013, para. 40 \& 63).

While government leadership is essential for the effective implementation of these Guidelines, it is important to note that the Guidelines are explicitly not limited only to governments, but toward “all sectors directly or indirectly concerned” (Guidelines, para. 2) including policy-makers, decision-makers, and professionals. There is, therefore, the potential for the Guidelines to function as an important advocacy tool as well.

While it is a significant achievement to agree on a legal framework and establish proactive guidelines such as these in relation to this important aspect of children's lives, it is the implementation of these Guidelines evidenced by actual changes to practices and systems which will ultimately make a felt difference to children's lived experiences. The development and welcoming of these Guidelines reflect one remarkable step; the implementation of the Guidelines is yet a different challenge completely. And implementation is our collective chief interest here: making sustainable improvements to services and systems to ensure that international policy makes a lasting and felt difference to the day-to-day lives of children out of their family's care.

\section{The Moving Forward Implementation Handbook}

Not long after the Guidelines were welcomed by the U.N. General Assembly, Moving Forward: Implementing the Guidelines for the Alternative Care of Children (Cantwell et al., 2012) was commissioned and supported by a range of international bodies with the intention to do just that: to move the Guidelines beyond their existence as an important international policy framework into developing practice that embeds children's rights in the provision of alternative care. CELCIS was commissioned to undertake this exciting work, and it was my privilege to lead the project. Translated into six languages (at time of writing), Moving Forward supports the implementation of the Guidelines by making clear connections between national policy, direct practice, and the Guidelines themselves. As the Guidelines do not entail a binding international treaty, the background drafting documents normally associated with these treaties are not available in relation to the Guidelines. In lieu of these "travaux préparatoires", Moving Forward offers insight into the intended meaning of the Guidelines. Its authority is drawn from the chief development role played by the project's lead consultant from their early beginnings and throughout their progress.

Moving Forward helps to "unpack" the Guidelines and brings to life some of the policy and practice challenges, as well as outlining some ways in which, around the globe, people at state level, in NGOs and civil society, have overcome these many challenges to ensure that improvements in alternative care gain momentum. Informed by a global 
consultation process, Moving Forward explains the principles and intentions behind the Guidelines' messages; it outlines the key national and regional policy orientations that are necessary as the basis for the implementation of the Guidelines; it examines particularly complex areas of practice, and gives examples of promising practice from around the world to inspire us to apply the Guidelines, regardless of economic stability, cultural contexts, or other circumstances. I will draw on Moving Forward in my outline of some of the key aspects of these Guidelines.

\section{Principles of the Guidelines}

The Guidelines offer both a powerful advocacy tool as well as a guide to how we collectively understand the whole system of alternative care for children. While the fundamental principles may not be unfamiliar, how they are crafted into an overarching framework offers a refreshing synthesis perspective on the context of the work we do and what we collectively aspire to achieve in partnership with children and families.

As Moving Forward explains, the Guidelines were created to ensure respect for two basic principles of alternative care for children, namely: "that such care is genuinely needed (the 'necessity principle'), and that, when this is so, care is provided in an appropriate manner (the 'suitability principle')” (Cantwell et al., 2012, p. 22). These principles emphasise the need for a fundamental prioritisation of efforts toward the prevention of separation as the key starting point, to ensure that alternative care is used only when necessary and is appropriate for the child concerned.

\section{Necessity}

Indeed, much of the Guidelines is devoted to the idea of preventing the need for alternative care. This means addressing a substantial range of issues including poverty, stigmatisation, discrimination, health, parent support, and family strengthening. It also requires the recognition of the vital role that informal traditional care mechanisms can have in ensuring care for a child who is not able, for whatever reason, to live with his or her parents. This is the starting point in the Guidelines, which aim to challenge our assumptions about what is necessary: what could we do further to ensure a child does not need formal care and that adequate measures for reintegration into the family are in place?

A robust "gatekeeping” mechanism makes certain that children are admitted to the alternative care system only if all possible means of keeping them with their parents or wider family have been examined. The implications here are twofold, requiring adequate services or community structures to which referrals can be made, and a gatekeeping system that can operate effectively regardless of whether the potential formal care provider is public or private. Among other issues, this is to protect against the consequences of providers themselves being gatekeepers for their own resources, which can unintentionally create an incentive to recruit and maintain numbers of children, and likewise risks creating a disincentive in supporting children to return to their kin.

\section{Suitability}

Once it has been determined that a child's needs are best met and their rights best realised through formal alternative care, this care must be provided appropriately for each individual child. That is, whether it is family-based or residential, the care provider must 
maintain a high quality of care for the children and - very importantly - the type of care that is provided must respond as best as possible to the specific needs and characteristics of the child. To uphold the suitability principle, "all care settings must meet general minimum standards" (Cantwell et al., 2012, p. 22). Ensuring this requires the establishing of standards as well as a mechanism and process to authorise providers of alternative care on the basis of this criteria. To monitor compliance, subsequent inspections also need to be carried out.

Matching the specific needs and characteristics of the child with the care setting means selecting the care provision that will best meet the child's needs, and regularly reviewing this decision with a view to the child's changing needs over time. A genuine choice must exist in order to effectively match the child to the care setting, hence a range of family-based and other care settings should be available. This leads us to a further fundamental principle of the Guidelines: "If deciding on 'suitability' is to be a meaningful exercise, there must clearly be a range of valid care options from which to choose" (Cantwell, et al., 2012, p. 71).

\section{Ensuring a range of options}

The Guidelines remind us that children need stability for their healthy development; so frequent changes in care settings must be avoided. For stability to be achieved, the range of options must first be available, then thoroughly assessed against the child's needs, and reviewed as the placement progresses.

This range of care options should exist "with priority to family and communitybased solutions” (U.N. General Assembly, 2009, para. 53 \& 54). Importantly, the Guidelines acknowledge that family-based settings and good quality residential care facilities form part of a range of appropriate responses, provided that the residential care facilities conform to certain specifications and are used only for "positive" reasons - that is, when they are the most appropriate response to the situation and the needs of the child concerned (U.N. General Assembly, 2009, para. 121, 126, \& 21; Cantwell et al., 2012, p. 22). In other words, a lack of other options, of time or of resources to find a more appropriate setting need to be addressed in their own right, and are not sufficient reasons for providing a child with a residential living situation.

Distinguishing between "residential facilities" and "institutions" is a sticky issue globally, and in some cases clear parameters and definitions are not easy to establish, and the concepts are not absolute. As Cantwell and colleagues (2012) note:

The term "institution" has generally taken on a very negative connotation, but there is still no international agreement on its definition: The CRC (Article 20) merely mentions "institutions" as the only example of a non family-based care setting, while the Guidelines simply use the term to describe "large residential facilities". (p. 42)

In addition to many NGO and U.N. reports, the Economist magazine (2013) recently called for faster reforms to institutions worldwide, citing them as "poisonous". The reasons offered include: the toxicity of the environment on children's health; the isolation it enforces on children from families and their communities; and the unnecessary costs. 
In truth, there is no universally agreed definition - in the Guidelines or elsewhere of what constitutes an "institution" as opposed to other residential care settings. According to the Guidelines, size is one factor, but this is largely because of the now well-documented negative impact that large-scale group care frequently has on the well-being and development of children, and on the capacity to safeguard and promote their rights. (Cantwell et al., 2012, p. 34)

Importantly, it is the "large residential facilities" or "institutions", and not residential facilities as a whole that are to be targeted through a "de-institutionalisation strategy" (U.N. General Assembly, 2009, para 23). Moving Forward asserts that it is most important to address head-on the cultures themselves that are institutional in nature; which are described as "the regimes and day-to-day organisation that take little account of individuality, or psychological and emotional needs, and tend to isolate children from the outside world" (Cantwell et al., 2012, p. 34). As this type of culture can also occur in smaller care homes, this broader understanding of institutional cultures should be the lens that is applied when determining whether a particular facility should be considered as an "institution"

\section{De-institutionalising the system}

It is difficult, if not impossible, to talk about developing a range of options without making reference to the very important task of deinstitutionalisation. In many countries these go hand-in-hand, as they should.

The Guidelines stipulate that nationally, to deinstitutionalise effectively, "suitability of care placements" cannot be a sufficient focus. That is, a focus on closing down institutions is insufficient. Instead, the Guidelines stipulate the need to "de-institutionalise the system"; this requires ensuring that the "necessity" and "gatekeeping” functions within the wider system are given adequate priority alongside developing a range of noninstitutional options. Working alongside governments to achieve this is imperative. Where this goal has been achieved, it has been a complex, complicated, and carefully planned process.

\section{Conclusions}

This presentation has offered introductory information about the Guidelines, alongside commentary and contextualising perspectives from Moving Forward, with the aim of supporting the Guidelines' implementation. A strengths-based, interactive implementation measuring tool, entitled Tracking Progress: Implementing the Guidelines for the Alternative Care of Children (Elsley, Davidson, Hill, Cantwell, \& Milligan, in press) is currently under development, which is aspiring to enable states - and their wide range of partners in the provision of alternative care - to adequately determine the extent to which they have implemented the Guidelines, as well as to identify their priority next steps.

I began by asking this question: What has changed in 10 years? And ultimately, until we consistently implement these Guidelines, genuine social inclusion for these children and young people around the world will continue to be elusive and at best, inconsistent. Together with partners, we can make sustainable changes happen, and the Guidelines offer us a new coherent and principled vision for our efforts. 


\section{References}

African Committee of Experts on the Rights and Welfare of the Child (ACERWC). (2013). General comment on Article 30 of The African Charter on The Rights and Welfare of the Child. ACERWC/GC/01. Addis Ababa: Author. Retrieved June 24, 2014 from http://acerwc.org/

Ainsworth, F., \& Thoburn, J. (2014). An exploration of the differential usage of residential childcare across national boundaries, International Journal of Social Welfare, 23(1), 16-24. http://dx.doi.org/10.1111/ijsw.12025

Cantwell, N., Davidson, J., Elsley, S., Milligan, I., \& Quinn, N. (2012). Moving forward: Implementing the guidelines for the alternative care of children. Glasgow: Centre for Excellence for Looked After Children in Scotland. Retrieved June 24, 2014 from http://www.alternativecareguidelines.org

Davidson, J. (2010). A bully in the playground: Examining the role of neoliberal economic globalisation in children's struggle to become 'fully human'. Law, Social Justice \& Global Development Journal, 16(2), Retrieved June 24, 2014 from http://www.go.warwick.ac.uk/elj/lgd/2010_2/davidson

Economist. (2013, August 17). Children's homes: the nanny state. Economist. Retrieved June 24, 2014 from http://www.economist.com/news/international/21583665orphanages-are-closing-not-quickly-enough-nanny-state

Elsley, S., Davidson, J., Hill, M., Cantwell, N., \& Milligan, I. (in press). Tracking progress: Implementing the guidelines for the alternative care of children.

Quinn, N., Davidson, J., Milligan, I., Elsley, S., \& Cantwell, N. (2014). Moving forward: Towards a rights-based paradigm for care leavers. International Social Work. doi: 10.1177/0020872814547439.

Thoburn, J. (2007). Globalization and child welfare: some lessons from a cross-national study of children in out-of-home care. Norwich: University of East Anglia.

United Nations. (1989). Convention on the rights of the child. New York: Author. Retrieved June 24, 2014 from www2.ohchr.org/english/law/crc.htm

United Nations Human Rights Council. (2012). Committee on the rights of persons with disabilities (eighth session). Geneva: Author. Retrieved June 24, 2014 from http://www.ohchr.org/EN/HRBodies/CRPD/Pages/Session8.aspx

United Nations General Assembly. (2009). Guidelines for the alternative care of children (Resolution A/RES/64/142). New York: Author. Retrieved June 24, 2014 from http://www.un.org/ga/search/view_doc.asp?symbol=A/RES/64/142 
International Journal of Child, Youth and Family Studies (2015) 6(3): 379-387

Zermatten, J. (2012). President of the U.N. Committee on the Rights of the Child introducing "Moving forward: Implementing the guidelines for the alternative care of children" (Video file). Retrieved June 24, 2014 from

http://www.alternativecareguidelines.org/MovingForward/IntroducingMovingForwa rd/tabid/2804/language/en-GB/Default.aspx 